\title{
A (IN)EFETIVIDADE DA MEDIAÇÃO FAMILIAR PARA A TUTELA DOS DIREITOS DA PERSONALIDADE DA CRIANÇA E DO ADOLESCENTE
}

\author{
http://dx.doi.org/10.21527/2176-6622.2021.55.89-102
}

Recebido em: 21/12/2019

Modificações solicitadas em: 26/5/2020

Aceito em: 3/6/2020

\author{
Diego Fernandes Vieira \\ Autor correspondente. Unicesumar - Universidade Cesumar. Av. Guedner, № 1.610 - \\ Jardim Aclimação. CEP: 87050-390. Maringá/PR, Brasil. http://lattes.cnpq.br/8603486646565986. \\ https://orcid.org/0000-0001-5351-9023. diego.vieira_180@hotmail.com \\ Carlos Alexandre Moraes \\ Unicesumar - Universidade Cesumar. Maringá/PR, Brasil.
}

\section{RESUMO}

Este artigo analisa os direitos da personalidade das crianças e dos adolescentes que são mediados pelos seus pais, estudando, para tanto, a conjuntura judiciária e o método da mediação aplicado neste cenário. Utilizando o método hipotético-dedutivo, o artigo parte da premissa de que a configuração em que a mediação se encontra atualmente acaba muito mais por violar os direitos da personalidade do que propriamente efetivá-los. Para se comprovar esta hipótese foram utilizados o critério qualitativo e a técnica de pesquisa bibliográfica. A pesquisa realizada revelou a atual desvirtuação da mediação familiar no Brasil, bem como a sua inadequada aplicação nos conflitos, sendo, ainda, verificado que os direitos da personalidade dos filhos são lesionados com tal cenário, sendo urgente uma mudança voltada para a resolução dos conflitos familiares que, em razão de sua natureza especial, tendem a envolver questões existenciais e imateriais, carregadas de sentimentos e angústias. Assim, este artigo alerta sobre um mal que assola o Direito das Famílias, explicando, ao mesmo tempo, a importância dos direitos da personalidade para o desenvolvimento humano, em especial da criança e do adolescente.

Palavras-chave: Conflito. Dignidade humana. Direitos da personalidade. Mediação. Processo civil.

\section{THE (IN)EFFECTIVENESS OF FAMILY MEDIATION TO THE PROTECTION OF CHILD AND ADOLESCENT PERSONALITY RIGHTS}

\section{ABSTRACT}

This article analyzes the personality rights of children and adolescents who are mediated by their parents, studying the judicial conjuncture and the method of mediation applied in this scenario. Using the hypothetical-deductive method, the article assumes that the current mediation configuration ends up violating personality rights rather than actually make it effective. To prove this hypothesis, the qualitative criterion and the bibliographic research technique were used. The research revealed the distortion of family mediation in Brazil, as well as its inadequate application in conflicts. It was also verified that the rights of the personality of children are injured with such scenario, being a change aimed at the resolution of family conflicts urgent, that because of its special nature, tends to involve existential and immaterial issues, marked by feelings and anxiety. Thus, this article warns of an evil that plagues the Family Law, while explain the importance of the personality rights for human development, especially of children and adolescents.

Keywords: Civil procedure. Conflict. Human dignity. Mediation. Personality rights.

\section{SUMÁRIO}

1 Introdução. 2 Dos fundamentos e objetivos da mediação no direito das famílias. 3 Os direitos da personalidade da criança e do adolescente negociados na mediação. $4 \mathrm{Da}$ (in)eficácia da mediação familiar ante a tutela dos direitos da personalidade da criança e do adolescente. 5 Conclusão. 6 Referências. 


\section{INTRODUÇÃO}

As alterações que ocorreram no mundo e, principalmente, no ambiente familiar e em sua formação, surgiram acompanhadas de necessidades que estão voltadas hoje muito mais para questões imateriais do que materiais, e, assim, verifica-se a urgência da adequação dos métodos de resolução de conflitos para a pacificação social e a entrega de uma tutela jurisdicional efetiva.

É inegável que o núcleo familiar é, antes de tudo, uma manifestação sociológica, cultural e, principalmente, social, antecedendo qualquer categorização ou limite jurídico. Por vezes, contudo, a leitura que o Direito faz da família é apenas um recorte específico desta expressão social de afetividade, que tem por objetivo proteger as pessoas ali inseridas.

As mudanças neste ambiente de desenvolvimento e afetividade são a gênese de diversos conflitos interpessoais, principalmente quando ocorre à ruptura do vínculo conjugal, que ocasiona a modificação da unidade familiar e, de forma reflexa, provoca traumas e consequências emocionais aos filhos.

Hodiernamente, muito discute-se sobre qual seria a melhor técnica para a resolução dos conflitos desta natureza, posto que o método tradicional utilizado pelo Judiciário é insuficiente para abarcar toda a dinamicidade e problemáticas advindas desta relação. E não poderia ser diferente, pois, no método heterocompositivo, o Estado-juiz atua como verdadeiro ditador diante das partes, por meio da "solução" proferida em uma sentença que nem sempre é a melhor ou a mais justa para o caso concreto.

Neste contexto, a mediação mostra-se como a via mais propensa para a melhor resolução do conflito familiar, uma vez que valoriza a comunicação e permite que as próprias partes resolvam e adéquem seus interesses para o bem tanto coletivo quanto individual. O Estado, no tocante ao Poder Judiciário, não pode deixar de tutelar e se aperfeiçoar na melhoria da justiça. Nesta perspectiva é que a execução dos chamados meios alternativos de solução de conflitos (re)surge, colocando-se como medida que pode contribuir para o alcance da justiça.

A justificativa deste trabalho se perfaz por meio da necessidade de proteção da criança e do adolescente inseridos no ambiente familiar de conflito e diante da constatação de uma parentalidade irresponsável e da incapacidade de o Poder Judiciário atender a estas demandas de forma satisfatória. Constata-se que a aplicação da mediação na prática forense tem se distanciado de seu propósito, sendo guiada com o objetivo de realização de acordo e para desafogar o Judiciário, e não propriamente para restabelecer a comunicação e o consenso entre as partes, que deveria ser a sua principal finalidade.

O problema de pesquisa reside em entender o instituto da mediação, bem como os direitos da personalidade envoltos no conflito familiar mediado e, ainda, compreender a situação fática em que este método de resolução de conflito se encontra, e se este realmente é efetivo. Tem-se como objetivo abordar a mediação familiar por meio de uma análise crítica voltada para a sua efetividade ante a resolução dos conflitos, visto o incentivo para a instituição deste método pelo Poder Judiciário, Poder Legislativo e órgãos administrativos, levando-se em consideração a dignidade humana, os direitos da personalidade e, principalmente, o núcleo mínimo de cuidados parentais perante a criança e o adolescente.

Para tanto, abordou-se, primeiramente, o instituto da mediação, perpassando pelo seu conceito, objetivo e aplicação no cenário familiar. Posteriormente, buscou-se analisar os direitos da personalidade voltados para os filhos, que, em muitos casos, são disputados pelos genitores nas sessões de mediação. Em seguida, buscou-se demonstrar a efetividade ou não deste método alternativo de resolução de conflitos diante da proteção e da efetivação do princípio da dignidade da pessoa humana, do melhor interesse do menor e também do acesso à justiça.

A pesquisa utilizou o método hipotético-dedutivo e a metodologia de pesquisa bibliográfica, pautando-se em métodos jurídicos, interpretativos, exegéticos e sistemáticos, tendo como foco a análise documental e bibliográfica do tema, nos âmbitos nacional e internacional, para, por meio do entendimento sobre o tema, apontar o abismo entre a teoria e a realidade posta (POPPER, 2013).

Argumenta-se aqui por um Direito das Famílias que abranja muito mais do que o que está previsto nos códigos, de modo a compreender e enaltecer a verdadeira dimensão do Direito, que não se limita simplesmente à lei posta, principalmente no que se refere às famílias. 


\section{DOS FUNDAMENTOS E OBJETIVOS DA MEDIAÇÃO NO DIREITO DAS FAMÍLIAS}

O pensamento enraizado na sociedade moderna é o da cultura da judicialização, que afirma que o indivíduo pode recorrer ao Poder Judiciário a todo o momento, cenário este que tem se mostrado insuficiente para a resolução de alguns conflitos. Considera-se que "o sistema tradicional, com seu maniqueísmo excludente, é autoritário, lento, desumano e predatório" (VASCONCELOS, 2017, p. 330).

É nesse contexto de necessidade, insuficiência dos tradicionais modelos e, principalmente, de falhas do Judiciário na resolução dos litígios de natureza existencial, que se faz urgente o entendimento e a aplicação dos métodos alternativos de solução de conflitos/interesses. Assim, o Estado, por meio do Poder Judiciário, não vem cumprindo seu dever de maneira satisfatória, de forma que acaba, consequentemente, por ferir mais direitos do que tutelá-los (CARDIN; RUIZ, 2017).

Em razão dessa crise, vive-se momento hiperdinâmico, de mudanças de paradigmas. É crise funcionando como corante para dar nova cor, nova vida e moldura ao quadro societário. Nessa mudança de modelos, observa-se que o Estado vem deixando de ser um Estado administrador para tornar-se num Estado gerenciador. Nessa contextualização, no campo da Justiça surge no horizonte a mediação (RUIZ, 2003, p. 33-34).

As decisões "por atacado", que se sustentam pela jurisprudência e não sobre o caso em apreço, em conjunto com a demora da prestação jurisdicional, acarretam a perda da efetividade das decisões jurídicas e, ainda, ocasionam o sentimento de injustiça e de descrença no Poder Judiciário como órgão que proporciona estabilidade social (MASCARENHAS, 2011). Pode-se, ainda, evidenciar outras dificuldades no que se refere ao processo judicial, por exemplo, valores relativos às custas processuais, aos honorários, sejam periciais ou advocatícios, além da demora na prestação jurisdicional, que inviabiliza a tutela dos direitos da personalidade e da dignidade das pessoas envolvidas na lide. É algo inevitável que "o Poder Judiciário, em meio à crise que vive, adote novos meios alternativos para a solução dos litígios" (LANÇANOVA, 2014, p. 173).

Diante do movimento de reestruturação do acesso à Justiça, Marinoni $(2008$, p. 28) pontua que "o acesso à justiça significa, ainda, acesso à manifestação e à orientação jurídicas e a todos os meios alternativos de composição de conflitos".

Hoje em dia não há como se falar em acesso à Justiça sem vislumbrar a utilização de métodos alternativos de solução de conflitos, visando assegurar e garantir a aplicação dos direitos ameaçados em questão, uma vez que cada vez mais o Judiciário vem sendo atravessado pelas justiças emergentes, nos âmbitos nacionais e internacionais, representadas por formas extra oficiais de tratamento das demandas. Não significa negar a prestação jurisdicional por parte do Estado, mas propor alternativas porventura até menos onerosas e mais rápidas para a satisfação das controvérsias, com métodos mais humanísticos, que garantam, com maior qualidade, a obtenção da justiça (MASCARENHAS, 2011, p. 23).

Em meio a todos estes métodos, pode-se destacar o instituto da mediação, que é conceituado por Haynes e Marodin (1996) como um processo que envolve uma pessoa devidamente capacitada e as partes em disputa. $\mathrm{O}$ acordo que pode surgir com o diálogo que é estabelecido será estruturado conforme a vontade das partes, de modo que permita a continuidade da relação restabelecida; todavia, o "motivo, o objetivo da mediação não pode ser um simples acordo, mesmo que satisfatório" (DINIZ, 2016, p. 232).

A mediação também pode ser entendida como método que se pauta em técnicas específicas de comunicação, "adequadas para a escuta qualificada, prestando-se, com muita eficácia, a concretizar o princípio constitucional de proteção à dignidade da pessoa humana e de proteção do Estado" (BARBOSA, 2015, p. 54). Consiste, ainda, em propiciar aos envolvidos a "percepção ampliada dos meandros da situação controvertida, protagonizar saídas produtivas para os impasses que os envolvem" (TARTUCE, 2019a, p. 197).

No direito argentino, a mediação é compreendida por Quirosa (1999, p. 21) como uma "negociación colaborativa, asistida por un tercero neutral. También puede decirse que la mediación es un procedimiento no adversarial, en que un tercero neutral ayuda a las partes a negociar para llegar a un acuerdo satisfactorio para ambas". 
Nesta linha de entendimento, Vasconcelos (2017) sustenta que a mediação é uma forma de se estabelecer o diálogo aberto entre os envolvidos, modificando as (pré)compreensões das questões controvertidas e abrindo novos caminhos a serem tomados. Assim, a mediação pode ser vista como um procedimento, que é inclinado para a autocomposição entre as partes, tendo como pano de fundo os vínculos afetivos e os conflitos advindos deste âmbito (WARAT, 2000).

A mediação, de forma ampla, deve almejar "a real diminuição da litigiosidade entre os pares, o empoderamento das partes na resolução de seus futuros conflitos e a internalização de que o conflito pode ser dirimido de forma autônoma, por cada um, sem se recorrer ao Poder Judiciário" (DINIZ, 2016, p. 233).

A figura do mediador encontra-se prevista em Capítulo próprio, mais especificamente na Seção V, entre os artigos 165 e 175 do Código de Processo Civil, figurando como um auxiliar da justiça, o que não afasta, porém, a possibilidade de sua atuação de forma extrajudicial para as resoluções de conflitos (BRASIL, 2015a).

Em que pese o Código de Processo Civil - CPC - ter possibilitado a mediação tanto no cenário judicial quanto extrajudicial, também ocorreu a aprovação da Lei no 13.140/2015, que reafirmou a importância e a necessidade da mediação como forma de solução dos conflitos familiares (BRASIL, 2015b). Desse modo, surge uma nova possibilidade para se alcançar a satisfação do litígio, de maneira mais justa, flexível e célere (SIQUEIRA; PAIVA, 2016).

O CPC encontra-se também alinhado aos termos da Resolução no 125/2010 do Conselho Nacional de Justiça (BRASIL, 2010), que modificou os paradigmas jurídicos de solução de conflitos e reafirmou a ineficácia do Poder Judiciário para a resolução de certas demandas, principalmente as de natureza familiar, que têm como cerne questões afetivas, existenciais e despatrimonializadas.

A administração da justiça passa por um colapso, e um dos motivos deste é o contexto dos intermináveis processos que se aglomeram, e até mesmo "cuando por fin se llega a sentencia definitiva, siempre ambas partes pierden en gastos, tiempo y esfuerzos" (COLERIO; ROJAS, 1998, p. 10).

Incumbe ao Direito (e, de forma reflexa, aos juristas) elaborar propostas que possam "conferir respostas adequadas ao corpo social que pretenda regular" (CALDERÓN, 2017, p. 38). A família é o lugar em que diversas relações pessoais se formam e se perfazem, não sendo algo estanque e, desta feita, a sociedade também não é estática, aspecto este que é e deve ser observado para a solução de eventuais problemas relacionais e conflitos de interesses (PEREIRA, 2005).

Os métodos de resolução ou transformação de conflitos, em especial, a mediação, que pode abranger "qualquer questão que envolva laços afetivos ou familiares entre as pessoas, como separação, divórcio, revisão de pensão, guarda de filhos, adoção, conflitos entre pais e filhos ou entre amigos, etc." (BRAGA NETO, 2019, p. 167).

A utilização da mediação no âmbito do Direito de Família, em conflitos que envolvem os cônjuges e, muitas vezes, estes e os filhos, é extremamente adequada, até mesmo pela natureza dos conflitos de interesses aí constatados. Nesse ambiente, a solução consensual, amigável, não adversarial, por meio da comunicação direta entre os cônjuges, é medida que se recomenda, pelas suas próprias vantagens (CARDIN; RUIZ, 2017, p. 301).

O intento da utilização da mediação no âmbito familiar tem por intuito a transformação da condição de conflito em cenário de pacificação. No âmbito judicial, esta prática tende a viabilizar "uma reflexão mais profunda e detalhada, evitando o grande volume de ações, que são propostas e que se findam por vontade das partes, exatamente por se terem iniciado de forma imatura" (GONÇALVES, 1998, p. 152-154). A mediação auxilia as pessoas envolvidas no conflito a repensarem suas posições perante o outro e ante todo o sistema familiar (FONKERT, 1999).

O método alternativo de solução de conflitos vem destacando-se como forma de proteção da dignidade da pessoa e dos direitos da personalidade, e como uma verdadeira ferramenta de pacificação de conflitos familiares. $O$ direito, principalmente o processual, depara-se com dificuldades na concretização da justiça para as partes no que se refere às nuances da família para com seus membros e destes para com a sociedade. Neste entendimento, Lima e Pelajo (2016, p. 224) lecionam que este fenômeno 
[...] relaciona-se ao evidente anacronismo entre o sistema de adjudicação e a natureza das demandas de família. Contextos familiares são permeados por subjetividade. A qualidade da interação entre os cônjuges/companheiros e demais familiares depende, invariavelmente, das contribuições oferecidas pelas pessoas ao longo da convivência. Atitudes mal compreendidas não raro ensejam reações desproporcionais, que retroalimentam a hostilidade recíproca, em uma escalada destrutiva da relação.

A mediação familiar mostra-se, portanto, como uma opção tanto para o Judiciário quanto para as partes, como solução para aqueles que buscam a resolução de pontuais conflitos familiares. Será na mediação que ocorrerá a reflexão sobre o problema e o diálogo com o outro, com o objetivo comum de encontrar vias de superação dos impasses, o que permite um verdadeiro empowerment, que significa exatamente essa dimensão de transformação.

De forma simplista, é um processo no qual as partes tomam para si a responsabilidade pela construção da resolução de seus próprios conflitos, residindo na mão destas todo o poder de decisão (FONKERT, 1999). A mediação familiar tem como característica levar em consideração as necessidades de cada parte, especialmente dos filhos menores, compreendendo a corresponsabilidade parental. Este processo se faz necessário quando da ruptura da comunicação, que, muitas vezes se dá pela separação (BARBOSA, 2014).

Deve-se lembrar que esta técnica visa a "atender a pessoas e não a casos" (BRAGA NETO, 2019, p. 153), dignificando as partes e as protegendo contra as ingerências do Judiciário. É um método que se integra ao sistema multiportas de resolução de conflitos e tem o intuito de complementar o Poder Judiciário (LIMA; PELAJO, 2016).

É preciso destacar que este método não tem por objetivo o acordo (BRAGA NETO, 2019), mas, sim, a finalidade de edificar uma nova realidade que se inicia com a resolução do conflito e a educação dos envolvidos para a solução de futuros desentendimentos, para que adquiram a capacidade de resolver suas próprias questões. "O que causa grande êxito nesse método de resolução de conflitos é justamente essa liberdade que as pessoas têm de, em comum acordo, chegar a uma resolução satisfatória" (BRITO; SILVA, 2017, p. 25-26). É por este motivo que um acordo pode surgir caso as partes assim anseiem (BRAGA NETO, 2019). O valor que se eleva é o da transformação dos indivíduos, que "trata como fundamental a questão da satisfação individual e o bem-estar coletivo" (ALDENUCCl, 2012, p. 118).

A mediação ocasiona grande impacto na melhoria da condição de vida das pessoas e, de forma reflexa, proporciona positivas consequências para a unidade familiar. A comunicação é o fator que transforma o conflito e é o elemento fundamental deste método não adversarial. Logo, não haverá neste cenário ganhador ou perdedor (LANÇANOVA, 2014). Na mediação "se trabaja exclusivamente sobre los intereses de los sujetos, tratado de afirmar las coincidencias y acercar las diferencias" (COLERIO; ROJAS, 1998, p. 10).

Sem sombra de dúvida, a mediação carrega consigo maior carga de efetividade, posto que suas características se voltam para suprir as necessidades de cada conflito (RUIZ, 2003). Assim, observa-se que "os meios alternativos de resolução de conflitos se fazem necessários na modernidade para concretização dos direitos dos cidadãos, respeitando a celeridade processual" (CASAGRANDE; TEIXEIRA, 2018, p. 394).

A falta de comunicação e espaço seguro e sincero para o diálogo no ambiente familiar ocasiona muitas consequências negativas; uma delas é o fim dos relacionamentos conjugais, que acaba por envolver mudanças na rotina de crianças e adolescentes (BRITO; SILVA, 2017). Depois deste rompimento conjugal e afetivo nascem diversas disputas entre as pessoas, principalmente envolvendo os direitos dos filhos. Em decorrência de que em toda separação causa certo dano ao menor, quanto mais conflituoso o ambiente mais severas serão as sequelas na formação da personalidade da criança e do adolescente.

Percebe-se que ainda há certo preconceito em relação à mediação, principalmente porque a sociedade vislumbra que uma sentença judicial será a única a lhe proporcionar a segurança jurídica que busca. "Apesar de ser a mediação uma ótima ferramenta de resolução de conflito, é imprescindível a maturidade e aceitação das partes a tal mecanismo, o que não representa uma realidade em nosso país" (MEDINA, 2017, p. 155).

Além disso, as pessoas ainda tendem à judicialização, entregando ao Poder Judiciário a obrigação de resolver seus conflitos, dissabores, mágoas e questões existenciais. Por este motivo é que se fala cada dia mais em uma mudança substancial deste cenário, seja por meio da mediação, oficinas de parentalidade, terapia, enfim, caminhos para que ocorra o diálogo e, assim, a real concretização do acesso à justiça. 


\section{OS DIREITOS DA PERSONALIDADE DA CRIANÇA E DO ADOLESCENTE NEGOCIADOS NA MEDIAÇÃO}

A dissolução da comunhão de vida entre os genitores, em sentido amplo, modifica a estrutura e a disposição familiar bem como o seu funcionamento, e, consequentemente, atinge os filhos, que passam por uma desestruturação emocional momentânea (MADALENO; MADALENO, 2018). Reside nesse cenário a disputa entre os genitores pela guarda do filho e, muitas vezes, estes se esquecem que o menor é uma pessoa, detentora de direitos, e não mero objeto à disposição deles.

Assim, advindo o rompimento do vínculo conjugal afetivo, os direitos dos filhos são colocados em pauta para, assim, se definir como se dará a vida destes daquele ponto em diante, como é o caso da definição da guarda jurídica e física, dos alimentos e do direito de visitas. A peculiaridade do instituto familiar deverá ser observada pelo Direito, se este tem o intuito de corresponder aos desafios impostos (BECK, 2010).

Sobre esta especificidade de tratamento que deve ser dado às questões familiares, Pinto $(2005$, p. 159) assevera que

As normas que, em coerência com o sentido do casamento ou da relação de filiação, estabelecem os deveres dos cônjuges entre si, ou os deveres e direitos dos pais e dos filhos, não são criadas pelo direito "ex nihilo"; são, pelo contrário, normas segregadas pela instituição familiar, como uma ordem concreta e natural, normas realizadoras de um sentido pré-jurídico - ou pelo menos anterior ao direito legislado - do organismo familiar. O legislador reconhece essa ordenação espontânea e natural da família. É esta característica que correntemente se traduz dizendo que o Direito de Família é um direito institucional.

A especial proteção da família também se perfaz pelo fato de que muitas vezes nela estão envolvidos direitos da criança e do adolescente, e estes recebem especial proteção, conforme mandamento previsto no artigo 227 da Constituição Federal (BRASIL, 1988). Ainda, o Código de Processo Civil de 2015 reservou Capítulo próprio para as demandas familiares, que se inicia no artigo 693 e vai até o artigo 699 (BRASIL, 2015a).

Será pelo esforço coletivo de todos os que militam no campo jurídico (advogados, promotores de Justiça, juízes, professores de Direito, entre outros) que poderá se alcançar uma real efetividade no que diz respeito à dignidade humana e aos direitos conferidos às pessoas (NUNES, 2018). Desta forma, quando não existe a adequada prestação jurisdicional, seja pelos meios tradicionais ou alternativos, impede-se que se concretizem todos os valores éticos e jurídicos que a dignidade humana visa a garantir.

Os direitos da personalidade têm como objetivo exatamente a proteção desta dignidade, pois será por meio desta que o ser humano irá se realizar no mundo fático. Nesse sentido, sustenta Souza e Fachin (2019, p. 332) "que os direitos da personalidade formalmente assegurados no ordenamento normativo brasileiro (na Constituição Federal de 1988, no Código Civil de 2002 ou em leis) atuam como protetores e efetivadores da dignidade da pessoa humana".

Pode-se afirmar que a personalidade "se resume ao conjunto de caracteres do próprio indivíduo; consiste na parte intrínseca da pessoa humana [...]. Através da personalidade, a pessoa poderá adquirir e defender os demais bens" (SZANIAWSKI, 2005, p. 70). Assim, entende-se os direitos da personalidade como: "a) os próprios da pessoa em si (ou originários), existentes por sua natureza, como ente humano, com o nascimento; b) e os referentes às suas projeções para o mundo exterior (a pessoa como ente moral e social, ou seja, em seu relacionamento com a sociedade)" (BITTAR, 2015, p. 41).

Muitos destes direitos referentes à criança e ao adolescente são "negociados" pelos genitores em sessões de mediação; por exemplo, o direito à integridade psicofísica e outros de forma reflexa. Hipoteticamente falando, essas sessões deveriam resolver a questão da melhor forma possível, "possibilitando a posterior convivência entre as partes, vencendo a paixão e a emoção que normalmente impera nos conflitos familiares, buscando-se a solução também pela razão" (OLIVEIRA; CARAPUNARLA, 2016, p. 116).

Um dos direitos da personalidade mais discutidos na mediação é o direito à integridade tanto física quanto psíquica (psicofísica) da criança e do adolescente, exatamente por este proteger a incolumidade do corpo e da mente. Objetiva-se, com este direito, a manutenção da higidez física e da lucidez mental da pessoa 
(BITTAR, 2015). Ainda, verifica-se o unitarismo neste direito no que se refere à integridade, pois "a análise da expressão integridade, quer sob o perfil físico, quer sob o aspecto psíquico, constitui os componentes indivisíveis da estrutura humana" (SZANIAWSKI, 2005, p. 473).

Este direito da personalidade encontra-se ligado às questões atinentes aos alimentos prestados pelos genitores ao menor, que é um direito personalíssimo. "Afinal, serve para garantir a sobrevivência de quem não tem condições de subsistir por si mesmo" (DIAS, 2017, p. 35). Pelo fato de que venter non patitur dilatonionem (a barriga não admite demora), a prestação alimentar é necessária e urgente, pois quando intempestiva, o menor, credor dos valores alimentares, poderá padecer (TARTUCE, 2019b).

Outra questão discutida em sede de mediação que interfere diretamente na integridade psicofísica do filho, é a definição da modalidade de guarda. A legislação vigente prima pela fixação da guarda compartilhada, "com especial atenção para a divisão do tempo de convivência dos pais em relação a seus filhos comuns, mas tendo sempre em vista as condições fáticas e os interesses da prole (CC, art. 1.583, § 2ㅇ)" (MADALENO, 2019, p. 439). A guarda, seja ela física ou jurídica, possibilita a preservação do afeto entre os filhos e seus pais, visando sempre o melhor para o menor, preservando-se a integridade física e psíquica deste, sendo verdadeiro diferencial para concretizar o princípio da dignidade humana nestas relações (LANGOSKI, 2011).

A guarda jurídica compartilhada refere-se às questões atinentes às tomadas de decisão, o que se traduz em um direito dos genitores de decidir sobre o futuro dos filhos. Já a guarda física compartilhada irá ser exatamente este tempo de convívio, lapso temporal em que o genitor estará em companhia do filho, embora a criança ainda resida unicamente com um dos pais (RAMOS, 2016).

O instituto da guarda prima pela higidez física, mas, principalmente, psíquica da criança e/ou adolescente, para que este possa ter o devido amparo de ambos os genitores, assegurando à prole os devidos cuidados (materiais e imateriais) que se exige para a estruturação da personalidade humana (MADALENO, 2019), rompendo-se, assim, com a antiga concepção de que a mãe é quem cuidará apenas das questões imateriais e o pai quem arcará com o ônus de suprir as necessidades materiais dos filhos (LAURIA, 2003). O que predomina nas famílias brasileiras, todavia, é a fixação da guarda unilateral (TARTUCE, 2019b), ou, ainda, a fixação de uma guarda compartilhada no papel, mas, na realidade, o que se concretiza é a unilateral em favor da mãe.

Outro direito da personalidade que se coloca em evidência durante a mediação é o direito ao respeito, que é um direito que "toda pessoa humana faz jus em quaisquer circunstâncias, na conservação do bom relacionamento necessário para a coexistência na sociedade" (BITTAR, 2015, p. 209). É vinculada a relação paterno-materno-filial por intermédio da primazia do princípio do melhor interesse do menor, que "não tem apenas a função de estabelecer uma diretriz vinculativa para se encontrar as soluções dos conflitos, mas, também, implica a busca de mecanismos eficazes para fazer valer, na prática, essas mesmas soluções" (LAURIA, 2003, p. 37).

Também se estende o direito ao respeito às questões atinentes ao poder familiar e, por óbvio, à parentalidade responsável, que deve ser exercitada pelos genitores sempre observando a pessoa do filho, sendo esta representada pelo dever dos pais de criar, educar e acompanhar o desenvolvimento dos infantes, despendendo-Ihes a atenção necessária para a formação de sua personalidade (CARDIN; SANTOS; GUERRA, 2014).

De forma sucinta, outro direito da personalidade, que é discutido por meio da mediação familiar, é o direito ao pleno desenvolvimento. "De ser dito ainda que a doutrina e a jurisprudência alemãs entendem que o direito ao livre desenvolvimento da personalidade compreende duas dimensões: o direito geral de personalidade e a liberdade geral de ação" (CANTALI, 2009, p. 218). Este liga-se embrionariamente à criança e ao adolescente no que se refere ao direito à convivência familiar, pois é por meio desta que se terá o pleno desenvolvimento desta pessoa, mantendo-se "a unidade familiar, sem deixar que a criança ou o adolescente continue tendo cobertas suas necessidades básicas" (MADALENO, 2019, p. 480) para o seu desenvolvimento.

Nesse viés protetivo reside o princípio da dignidade humana, que atua na forma de uma cláusula geral de tutela da personalidade, protegendo o ser em todos os seus desdobramentos e nuances (SZANIAWSKI, 2005). A previsão constitucional desta dignidade e modificação valorativa do Estado eleva a pessoa, sua vida e bem-estar como pontos de referência para a atuação tanto estatal quanto particular. "A efetividade do princípio da dignidade humana se dá por via da concretização dos direitos fundamentais" (SOUZA; FACHIN, 2019, p. 330). 
Ou seja, esta questão voltada para a família modifica a sua função, que passa a ser a de realização afetiva dos seus integrantes e o desenvolvimento destes, de forma particular e coletiva. "A função afetiva da família é o que está a imperar, com proeminência crescente. Em vista disso, é possível afirmar que, atualmente, a afetividade perfila tanto na estrutura como na função das famílias hodiernas" (CALDERÓN, 2017, p. 167).

O menor, alocado na relação paterno-materno-filial, já não é mais concebido como propriedade dos genitores ou objeto à disposição destes, mas, sim, como detentor de direitos, pessoa em seu mais amplo sentido, possuidora de dignidade e merecedora de respeito.

A criança e o adolescente são sujeitos de direitos com prioridade em relação aos demais. Os seus interesses estão acima dos interesses dos pais. A responsabilidade conjunta e o carinho com o filho devem ser exercidos por ambos os genitores. Presumiu o legislador que a guarda compartilhada é a guarda que melhor atende aos interesses da criança (RAMOS, 2016, p. 74).

Destaca-se, ainda, que não cabe apenas aos genitores primar pelo bem-estar e proteção dos direitos de seus filhos, mas também à sociedade e, principalmente, ao Estado, tendo em vista o mandamento previsto no artigo 227 da Constituição Federal (BRASIL, 1988). Assim, pode-se preceituar a existência de "um elemento de conexão, chamado de democracia, a qual estabelece direitos aos indivíduos, na mesma proporção deveres aos Estados em garantir que tais direitos sejam efetivados através de políticas públicas" (CASAGRANDE; TEIXEIRA, 2018, p. 393). "Hoje, a mediação é reconhecida como política pública, pelo Conselho Nacional de Justiça, como meio eficaz e alternativo de solução dos conflitos" (LANÇANOVA, 2014, p. 173).

Logo, compreende-se que a mediação é o caminho para uma nova ótica perante os conflitos familiares e para a salvaguarda do direito ao acesso à justiça, fomentando-se, por meio dela, a paz e os atos de cidadania (LANGOSKI, 2011), premissa esta que é umbilical à manutenção do Estado Democrático de Direito, exatamente por levar em consideração todos os sentimentos envolvidos na problemática e compreender as diferenças que existem entre as partes da lide (SAMPAIO JÚNIOR, 2011).

Teoricamente falando, a mediação é um maravilhoso método a ser aplicado, que se pauta de minuciosa técnica e cuidado para com a vida humana e os direitos e pessoas envolvidas. O que se observa, entretanto, é que as mudanças legislativa, administrativa e/ou judicial, "não proporcionam uma mudança cultural na forma de administração da justiça; pelo contrário, burocratizam a forma consensual da atividade técnica da Mediação e mantêm a reprodução da cultura judicializada sob o manto do Poder Judiciário" (RODRIGUES; GONÇALVES; LAHOZ, 2018, p. 111). Assim sendo, entre a teoria e a prática existe um enorme abismo que tem se mostrado como o seu maior obstáculo a ser enfrentado.

\section{DA (IN)EFICÁCIA DA MEDIAÇÃO FAMILIAR ANTE A TUTELA DOS DIREITOS DA PERSONALIDADE DA CRIANÇA E DO ADOLESCENTE}

O Código de Processo Civil de 2015 estipula, em seu artigo 319, VII, que a inicial deverá indicar de forma expressa que o autor deseja que ocorra a realização ou não da audiência de conciliação ou mediação antes de se adentrar, de fato, no processo contencioso, alinhando-se tal mandamento com a nova tendência que se enraíza no Poder Judiciário, que é a de incentivar a conversação entre as partes, para que estas, de forma consensual, encontrem uma solução para os seus conflitos (BRASIL, 2015a).

No ano de 2010, por meio da Resolução no 125 do Conselho Nacional de Justiça, reconheceu-se a necessidade de aplicação de meios alternativos de resolução de conflito com foco nos consensuais, que se configuram como política pública que tem por escopo a efetivação da via mais adequada para a resolução dos diversos tipos de conflitos (BRASIL, 2010).

O incentivo para a autocomposição mostra-se muito mais presente nos processos familiares, a fim de concretizar direitos e não apenas de impor a resolução por meio de uma sentença. Confirma-se, assim, que as alterações trazidas pelo novo Código de Processo Civil de 2015 refletem principalmente no âmbito do Direito de Família e Sucessões, com a finalidade precípua de concretização de direitos (ARAÚJO; OLIVEIRA SOBRINHO, 2017). 
Os conflitos advindos de uma relação familiar carregam grande carga emocional, exatamente pelo fato de que abarcam sentimentos reprimidos, mágoas, traumas, dores, entre outros, que surgem com o dia a dia e a soma de fatores e acontecimentos (BRITO; SILVA, 2017). Por este motivo, mostra-se questionável o fato de que um juiz possa magicamente, com uma simples sentença, resolver todas essas questões emocionais e subjetivas.

A família é um complexo e peculiar instituto, e o direito envolto a esta é sempre uma redução do que se perfaz na realidade, sendo um recorte que engloba somente parte do todo que se desenvolve no corpo social (LYRA FILHO, 2006). A família precede o Direito, o que é um fato incontestável. Por esta justificativa é que o direito e sua interpretação devem captar e absorver as alterações sociais e relacionais, e não o contrário (CALDERÓN, 2017).

Observa-se que a mediação e a conciliação vieram exatamente de encontro com essa adaptação do direito às demandas familiares, reafirmando que o objetivo da mediação não é a celebração de um acordo, mas, sim, que as partes mediadas consigam restabelecer o diálogo (SIQUEIRA; PAIVA, 2016; TARTUCE, 2019a; VASCONCELOS, 2017; BARBOSA, 2015).

O mediador possui a função pedagógica, sendo incumbido de transformar o sentimento destrutivo que se assenta na lide, a fim de que seja semeada a pacificação (SIQUEIRA; PAIVA, 2016), devendo-se buscar muito mais a cultura da paz entre as partes do que a resolução propriamente dita e, acima de tudo, a desconstrução e amenização do fato que causou o litígio, capacitando as pessoas para lidarem com seus sentimentos internos e relacionamentos interpessoais.

Quando bem conduzida e aplicada, a mediação é capaz de tornar o direito algo acessível, garantindo a proteção de direitos de personalidade e, consequentemente, a preservação da dignidade humana de todas as pessoas envolvidas. "Mediante esse procedimento, as partes são introduzidas à cultura da administração pacífica de seus próprios problemas, à conversão de um conflito de interesses em possibilidades reais" (ZAPPAROLLI, 2003, p. 53).

Assenta-se, todavia, no Poder Judiciário, uma visão distorcida sobre qual seria o objetivo da mediação, tanto que, em 2005, o ministro Edson Vidigal, então presidente do Superior Tribunal de Justiça (STJ), colocou o uso da mediação e da conciliação como meios que serviriam para desafogar o Judiciário e, assim, otimizar o julgamento das ações (BARBOSA, 2015). A mediação não é e nunca teve por intuito esta função reducionista de "desafogar o Judiciário". Ela vai muito além, sendo um método interdisciplinar, regido por princípios e técnicas próprias, que visa, principalmente, o restabelecimento da comunicação do que propriamente a composição de um acordo a ser homologado pelo juiz.

A realidade jurídica mostra-se bem distante da teoria relacionada à mediação familiar, fazendo-se urgente a manutenção do núcleo deste instituto de resolução de conflito. O que se deve entender é que forçar, ou até mesmo criar situações para incitar a celebração de acordos entre pessoas vulneráveis, é um ato totalmente reprovável no âmbito jurídico (TARTUCE, 2017). O legislador, de forma pontual, vedou qualquer prática de constrangimento ou intimidação perante as partes para que se conciliem, conforme artigo 165 , §2ㅇ da Lei no 13.105/2015 (BRASIL, 2015a).

As condutas supraelencadas são de um todo inadequadas, pois objetivam apenas "pseudoacordos" que colaboram para macular o verdadeiro intuito da mediação, bem como a visão que a sociedade possui sobre este método (TARTUCE, 2017), além de violar todo o sistema legal sobre o qual se assenta na segurança jurídica.

Neste viés, nas palavras de Barbosa (2015, p. 104):

[...], a assertiva de que a mediação se presta a "desafogar o Poder Judiciário" representa um desserviço, afastando a compreensão do objetivo de estudo de significativa produção doutrinária. [...] A mediação não se presta para essa função reducionista de "desafogar o Judiciário", posto que se trata de um conhecimento ampliado pela interdisciplinaridade, capaz de concretizar a principiologia fundamental para a interpretação das normas jurídicas, tais como o princípio da dignidade da pessoa humana, o princípio do livre desenvolvimento da personalidade.

Todas essas falhas e inadequação na aplicação da mediação no âmbito familiar advêm exatamente da natureza patrimonialista que permeia todo o processo civil e a cultura jurídica. Desta forma, não é viável que se perpetue a "manutenção de regras estritamente patrimoniais para efetivação dos direitos materiais de cunho existencial" (MEDINA, 2017, p. 45). 
Pelo contrário, é urgente a superação da cultura do pensamento patrimonialista e elitista pelos operadores do direito, sejam eles advogados, juízes, promotores, enfim, todo o Poder Judiciário, para que, assim, se caminhe para uma cultura emancipatória, de pacificação e realização dos direitos humanos (VASCONCELOS, 2017; RUIZ; NUNES, 2014). Caso uma mudança paradigmática das instituições não ocorra, somente se estará reiterando a violação de direitos, a infelicidade das partes e a condenação do menor vulnerável a uma vida de sofrimento.

Desta forma, o Poder Judiciário necessita adaptar-se às demandas familiares e pensar no método de mediação como um complemento, e não como de exclusão destas. A compreensão dos juízes ante o método alternativo de resolução de conflito, qual seja, a mediação, acarretará em uma modificação na aplicação e condução desta técnica (SAMPAIO JÚNIOR, 2011), de modo a tentar aproximar a teoria da prática, tendo como premissa que o Direito "no puede ofrecer respuestas muertas a problemas vivos" (MORSELLO, 2000, p. 4-5).

É necessário compreender que, para que a mediação alcance os objetivos, é preciso que "o mediador esteja capacitado com noções de psicologia, nas técnicas de negociação, principalmente nos moldes da negociação baseada em princípios, no caso da mediação conhecida como facilitadora" (RUIZ; NUNES, 2014. p. 86).

A forma, contudo, como esta técnica de resolução de conflito é conduzida no mundo fático, principalmente no cenário judicializado, somente gera mais danos aos mediados, desvirtua o objetivo da mediação e faz a sociedade desacreditar na Justiça. Uma "mediação" que ocorre no tempo de, no máximo, 15 minutos, em uma única sessão, ou que se inicia com a indagação se as partes possuem uma proposta de acordo, não se configura em verdadeira mediação familiar, tampouco uma conciliação, mas somente um pseudoacordo (TARTUCE, 2019a).

Tal atitude somente prejudica a criança e o adolescente ali inseridos e envolvidos na lide, e acarreta danos aos seus direitos da personalidade, afrontando-se, assim, o pilar estruturante do Estado Democrático de Direito, que é a dignidade humana. Por este fato, o mediador necessita promover, entre os mediados, "a possibilidade de convidá-los a debater outros temas tão importantes quanto aquele que os trouxe para a mediação, para que se alcance toda a complexidade das questões identificadas" (BRAGA NETO, 2019, p. 156).

Espera-se uma mudança de paradigma para com os conflitos familiares e, assim, que as pessoas e seus advogados possam optar pelos meios alternativos de resolução de conflitos. É essencial que o Estado, em seu sentido lato, compreenda que existem limites, e estes impedem que se forcem situações que tenham como intento promover o consenso a todo custo (TARTUCE, 2017). Excluir ou renegar os mecanismos alternativos, portanto, não é a saída, mas também acreditar veemente que eles são a salvação de um sistema ineficiente é o mesmo que incorrer no esvaziamento da própria atribuição jurisdicional (MEDINA, 2017). Conforme compreendem Oliveira e Carapunarla (2016, p. 166),

É certo, porém, que sem uma estrutura física compatível, sem um preparo dos facilitadores em cursos específicos, de nada adianta as modificações elencadas pela nova legislação processual. O Estado deverá proporcionar meios adequados para que a mediação e conciliação possam ser levadas a efeitos nos moldes idealizados, tais como propiciar o mínimo de suporte material, estímulo, treinamento, inclusive com a previsão de remuneração dos mediadores e conciliadores, sob pena de perecer todo o esforço legislativo até então empreendido.

Logo, entende-se que a mediação tem como fundamento o diálogo, sendo este o método de resolução de conflito "que se mostra mais eficaz, com numerosas vantagens para as pessoas" (CARDIN; RUIZ, 2017, p. 303) envolvidas na lide, quando se tem como cenário questões familiares que são carregadas de sentimentos negativos e positivos e, principalmente, vínculo afetivos entre as partes.

Pode-se concluir que "a adoção dos meios alternativos como forma de efetivo acesso do cidadão à justiça só será realmente possível na cultura jurídica brasileira quando trabalhada desde a educação dos operadores do Direito, nos mais diversos cursos existentes no país" (RODRIGUES; GONÇALVES; LAHOZ, 2018, p. 109). É necessária uma mudança de paradigma do cenário jurídico atual, especialmente em respeito ao princípio da dignidade humana, posto que a mediação tem por finalidade devolver aos mediados a capacidade de resolução de seus próprios conflitos.

A justiça pós-moderna não se restringe apenas às normas elencadas em leis e atos normativos. "É preciso criar uma consciência de que o direito do cidadão deve ser respeitado" (CASAGRANDE; TEIXEIRA, 2018, p. 388), e, principalmente, o direito da criança e do adolescente, que se encontram nessa situação de vulnerabilidade, tendo seus direitos negociados e acordados por seus genitores, que, muitas vezes, não primam pelo melhor interesse do menor. 


\section{CONCLUSÃO}

Esta pesquisa teve como foco analisar os direitos da personalidade infantojuvenis que são tratados em uma mediação familiar, entender este método alternativo de resolução de conflito e a sua efetividade no plano prático, concluindo pela latente necessidade de uma reconfiguração deste mecanismo, principalmente no cenário judicial, protegendo-se e tutelando a dignidade da pessoa humana, tanto dos mediados quanto de seus filhos.

Nesse panorama, constatou-se, por meio da pesquisa, que o Direito não é um instituto perene, estável e imutável, mas que está sempre em construção e adequação com a sociedade e necessidades de seu tempo, tendo como principal objetivo a justiça e o bem-estar tanto coletivo quanto individual.

A comunicação entre as pessoas, todavia, é a principal chave para abrir as portas para uma sociedade mais harmônica e fraterna, não se podendo incumbir o Estado de todas as mazelas e, muito menos, esperar que o Poder Judiciário resolva todos os problemas familiares, sejam eles de cunho patrimonial ou existencial.

É fato que os casais, atualmente, tendem a resolver seus problemas de natureza familiar da maneira mais inadequada possível, sem diálogo, respeito e/ou preocupação com os filhos menores, que são incluídos no dilema familiar e nada podem fazer para minimizar a animosidade dos genitores.

Diante deste entendimento é que se intentou a introdução da mediação como forma de resolução de conflitos familiares, a fim de restabelecer a comunicação entre as partes e, assim, capacitá-las para a resolução dos litígios presentes e futuros. Da forma, contudo, com que fora introduzida no Judiciário brasileiro, esta foi desvirtuada, sendo transformada em uma ferramenta para a concretização de acordos, com o claro objetivo de "desafogar o Judiciário", e não pode possibilitar o empoderamento e o crescimento dos mediados.

Reconhece-se, assim, que a aplicação da mediação no cenário familiar é ineficaz e desvirtuada, necessitando que os mediadores sejam capacitados para tanto, bem como é fundamental a maior compreensão dos magistrados e, principalmente, melhor postura dos advogados em relação ao método para uma mudança significativa que objetive o alcance da justiça nos conflitos envoltos ao Direito das Famílias.

Desse modo, é nítida a necessidade do resgate dos objetivos e da finalidade do Poder Judiciário, bem como da própria mediação, para que modifique as lentes do Direito patrimonialista de forma a redirecioná-las para um Direito existencial que reflita as demandas familiares que envolvem a afetividade e o cuidado. Apenas assim é que se alcançará justiça para as partes e a real proteção da criança e do adolescente.

O diálogo e a comunicação entre os genitores, assim como o resgate da afetividade e do cuidado para com os filhos, contribuirão não apenas para a resolução do conflito ali instalado, mas para a restruturação da unidade familiar, sendo a resposta para os atuais problemas familiares que o direito hoje enfrenta. Enfim, a felicidade, tanto dos genitores quanto de seus filhos, não pode ser sufocada pela violência ou pelo desrespeito, mas semeada com a cultura da paz.

A dignidade humana e os direitos da personalidade da criança e do adolescente que estejam no meio de toda a disputa entre os genitores, somente será respeitada quando se entender que o acesso à justiça, seja por meio do Poder Judiciário ou pelos métodos alternativos de solução de conflito, só se concretizará quando a mediação familiar realmente for exercitada, restabelecendo a comunicação entre os mediados para que entendam suas responsabilidades diante dos filhos, e que a comunicação e a maturidade emocional são os pilares para a solução de qualquer conflito.

\section{REFERÊNCIAS}

ALDENUCCI, Lidercy Prestes. Mediação de conflitos familiares. In: BRAGA NETO, Adolfo; SALES, Lilia Maia de Moraes (org.). Aspectos atuais sobre a mediação e outros métodos extra e judiciais de resolução de conflitos. Rio de Janeiro: GZ Editora, 2012. p. 107-126.

ARAÚJO, Mercedes Ferreira de; OLIVEIRA SOBRINHO, Afonso Soares de. Direito de família e sucessões no código de processo civil/2015: a primazia da mediação para uma cultura do diálogo. Revista de Formas Consensuais de Solução de Conflitos, Brasília, v. 3, n. 1, p. 51-72, jan./jun. 2017. Disponível em: https://indexlaw.org/index.php/revistasolucoesconflitos/article/ view/2111/pdf. Acesso em: 19 dez. 2019. 
BARBOSA, Águida Arruda. Guarda compartilhada e mediação familiar: uma parceria necessária. Revista Nacional de Direito de Familia e Sucessões, v. 1, 2014. Disponível em: http://www.fernandatartuce.com.br/wp-content/uploads/2016/01/Aguida-Arruda-Barbosa-Guarda-Compartilhada-e-media\%C3\%A7\%C3\%A3o-familiar-parceria.pdf. Acesso em: 25 ago. 2019.

BARBOSA, Águida Arruda. Mediação familiar interdisciplinar. São Paulo: Atlas, 2015.

BAUMAN, Zygmunt. Modernidade líquida. Tradução Plínio Dentzien. Rio de Janeiro: Zahar, 2001.

BECK, Ulrich. Sociedade de risco: rumo a uma outra modernidade. Tradução Sebastião Nascimento. São Paulo: $34,2010$.

BITTAR, Carlos Alberto. Os direitos da personalidade. 8. ed. São Paulo: Saraiva, 2015.

BRAGA NETO, Adolfo. Mediação de Conflitos: Conceito e Técnicas. In: SALLES, Carlos Alberto de; LORENCINI, Marcos Antônio Lopes; SILVA, Paulo Eduardo Alves da (org.). Negociação, mediação, conciliação e arbitragem: curso de métodos adequados de solução de controvérsias. 2. ed. Rio de Janeiro: Forense, 2019. p. 149-171.

BRASIL. (Constituição [1988]). Constituição da República Federativa do Brasil. Brasília, DF: Presidente da República, 2016. Disponível em: http://www.planalto.gov.br/ccivil_03/constituição/constitui\%C3\%A7ao.htm. Acesso em: 20 set. 2019.

BRASIL. Lei n. 8.069, de 13 de julho de 1990. Dispõe sobre o Estatuto da Criança e do Adolescente e dá outras providências. Brasília, DF, Presidência da República, 2019. Disponível em: http://www.planalto.gov.br/ccivil_03/leis//8069.htm. Acesso em: 5 ago. 2019.

BRASIL. Lei n. 10.406, de 10 de janeiro de 2002. Institui o Código Civil. Brasília, DF, Presidência da República, 2018. Disponível em: http://www.planalto.gov.br/ccivil_03/leis/2002/l10406.htm. Acesso em: 20 set. 2019.

BRASIL. Lei no 13.105, de 16 de março de 2015. Código de Processo Civil. Brasília, DF, Presidência da República, 2015a. Disponível em: http://www.planalto.gov.br/ccivil_03/_ato2015-2018/2015/lei//13105.htm. Acesso em: 15 set. 2019.

BRASIL. Lei no 13.140, de 26 de junho de 2015. Dispõe sobre a mediação entre particulares como meio de solução de controvérsias e sobre a autocomposição de conflitos no âmbito da administração pública; altera a Lei no 9.469 , de 10 de julho de 1997, e o Decreto oㅜ 70.235, de 6 de março de 1972; e revoga o § 2o do art. 6ㅇ da Lei no 9.469, de 10 de julho de 1997 . Brasília, DF, Presidência da República, 2015b. Disponível em: http://www.planalto.gov.br/ccivil_03/_Ato2015-2018/2015/Lei/L13140. htm. Acesso em: 15 set. 2019.

BRASIL. Conselho Nacional de Justiça. Resolução no 125, de 29 de novembro de 2010. Brasília, DF: CNJ, 2010. Assunto: Dispõe sobre a Política Judiciária Nacional de tratamento adequado dos conflitos de interesses no âmbito do Poder Judiciário e dá outras providências. Disponível em: https://www.cnj.jus.br/wp-content/uploads/2016/03/resolucao_125_29112010_11032016150808.pdf. Acesso em: 10 out. 2019.

BRITO, Marcella Mourão de; SILVA, Alexandre Antonio Bruno da. A mediação familiar e o fim do relacionamento conjugal: o problema do acesso à justiça e a experiência das oficinas de parentalidade. Revista de Formas Consensuais de Solução de Conflitos, v. 3, n. 2, p. 19-36, jul./dez. 2017. Disponível em: https://www.indexlaw.org/index.php/revistasolucoesconflitos/article/ view/2255/pdf. Acesso em: 19 dez. 2019.

CALDERÓN, Ricardo Lucas. Princípio da afetividade no direito de família. 2. ed. Rio de Janeiro: Forense, 2017.

CAMPOS, Diogo Leite de. A nova família. In: TEIXEIRA, Sálvio de Figueiredo (coord.). Direitos de família e do menor: inovações e tendências - doutrina e jurisprudência. 3. ed. Belo Horizonte: Del Rey, 1993.

CANTALI, Fernanda Borghetti. Direitos da personalidade: disponibilidade relativa, autonomia privada e dignidade humana. Porto Alegre: Livraria do Advogado, 2009.

CARBONERA, Silvana Maria. O papel jurídico do afeto nas relações de família. In: FACHIN, Luiz Edson (coord.). Repensando os fundamentos do direito civil contemporâneo. Rio de Janeiro: Renovar, 1998. p. 297-298.

CARDIN, Valéria Silva Galdino; RUIZ, Ivan Aparecido. Da mediação na alienação parental. Revista Em Tempo, v. 16, n. 1, p. 287306, 2017. Disponível em: https://revista.univem.edu.br/emtempo/article/view/2424. Acesso em: 28 set. 2019.

CARDIN, Valeria Silva Galdino; SANTOS, Andréia Colhado Gallo Grego; GUERRA, Marcela Gorete Rosa Maia. Dos reflexos da crise do direito liberal na atualidade quando do exercício da parentalidade responsável. Revista Direito e Justiça: Reflexões Sociojurídicas, ano 16, n. 23, p. 131-148, nov. 2014.Disponível em: http://srvapp2s.santoangelo.uri.br/seer/index.php/direito_e_justica/article/view/1526/699. Acesso em: 19 dez. 2019.

CASAGRANDE, Jéfferson Ferreira; TEIXEIRA, Rodrigo Valente Giublin. O papel do Poder Judiciário na contemporaneidade e seu reflexo na dignidade da pessoa humana. Revista Pensamento Jurídico, v. 12, n. 2, p. 375-396, jul./dez. 2018. Disponível em: https://fadisp.com.br/revista/ojs/index.php/pensamentojuridico/article/view/155. Acesso em: 27 set. 2019.

COLERIO, Juan Pedro; ROJAS, Jorge A. Mediación obligatoria y audiencia preliminar. Buenos Aires: Rubinzal-Culsoni Editores, 1998.

DIAS, Maria Berenice. Alimentos: direito, ação e execução. 2. ed. São Paulo: Revista dos Tribunais, 2017.

DINIZ, Bárbara Silva. Mediação judicial de conflitos - um estudo de caso sobre desafios institucionais. Revista Direito em Debate, v. 25, n. 46, p. 207-237, 2016. Disponível em: https://www.revistas.unijui.edu.br/index.php/revistadireitoemdebate/article/ view/6014. Acesso em: 29 out. 2019. 
FACHIN, Luiz Edson. Estabelecimento da filiação e paternidade presumida. Porto Alegre: Fabris, 1992.

FACHIN, Luiz Edson. Teoria crítica do direito civil. 2. ed. Rio de Janeiro: Renovar, 2003.

FONKERT, Renata. Mediação familiar: Recurso alternativo à terapia familiar na resolução de conflitos em famílias com adolescentes. In: SCHNITMAN, Dora Fried; LITTLEJOHN, Stephen (orgs). Novos paradigmas em mediação. Porto Alegre: Artmed, 1999, p. 169-184..

GONÇALVES, W. J. União estável e as alternativas para facilitar a sua conversão em casamento. São Paulo: [s.n.], 1998.

HAYNES, John M.; MARODIN, Marilene. Fundamentos da mediação familiar. Porto Alegre: Artes Médicas, 1996.

LANÇANOVA, Jônatas Luís. O poder judiciário em crise e a mediação como meio alternativo de solução dos conflitos. Revista Direito em Debate, v. 23, n. 42, p. 150-175, 2014. Disponível em: https://www.revistas.unijui.edu.br/index.php/revistadireitoemdebate/article/view/2901. Acesso em: 25 out. 2019.

LANGOSKI, Deisemara Turatti. Contribuições da extensão para a consolidação dos direitos humanos. Revista Dialogos, Brasília, v. 16, n. 2, dez. 2011.

LANGOSKI, Deisemara Turatti. A mediação familiar e o acesso à justiça. Revista Diálogos, v. 16, n. 2, p. 8-17, 2013. Disponível em: https://bdtd.ucb.br/index.php/RDL/article/view/3413/2946. Acesso em: 10 out. 2019.

LIMA, Evandro Sousa e; PELAJO, Samantha. A mediação nas ações de família. In: ALMEIDA, Diogo Assumpção Rezende de; PANTONA, Fernanda Medina; PELAJO, Samantha (coord.). A mediação no Novo Código de Processo Civil. 2. ed. Rio de Janeiro: Forense, 2016. p. 2-306.

LAURIA, Flávio Guimarães. A regulamentação de visitas e o princípio do melhor interesse da criança. 2. ed. Rio de Janeiro: Lumen Juris, 2003.

LINCK, Delfina. El valor de la mediación. Buenos Aires: Ad-hoc, 1997.

LYRA FILHO, Roberto. O que é direito. São Paulo: Brasiliense, 2006.

MADALENO, Rolf. Direito de família. 9. ed. Rio de Janeiro: Forense, 2019.

MADALENO, Ana Carolina Carpes; MADALENO, Rolf. Síndrome da alienação parental: importância da detecção - aspectos legais e processuais. 5. ed. Rio de Janeiro: Forense, 2018.

MARINONI, Luiz Guilherme. Novas linhas do Processo Civil. 4. ed. São Paulo: Malheiros, 2000.

MASCARENHAS, Fabiana Alves. Mediação familiar: por uma nova cultura de pacificação social. Lex Humana, v. 3, n. 2, p. 20-39, 2011. Disponível em: http://200.156.15.185/seer/index.php/LexHumana/article/view/175. Acesso: 27 set. 2019.

MEDINA, Valéria Julião Silva. Processo de família e o novo CPC: prática processual versus direito material. Curitiba: Juruá, 2017. MORSELLO, Augusto Mario. Derecho de daños. Buenos Aires: Scotti, 2000.

MORAES, Maria Celina Bodin de. Danos morais em família? Conjugalidade, parentalidade e responsabilidade civil. In: MORAES, Maria Celina Bodin de. Na medida da pessoa humana. Rio de Janeiro: Renovar, 2010. p. 71-120.

NEVES, Daniel Amorim Assumpção. Novo CPC - Novo Código de Processo Civil (Lei n. 13.105/2015): inovações, alterações e supressões comentadas. São Paulo: Método, 2015.

NUNES, Rizzatto. O princípio constitucional da dignidade da pessoa humana: doutrina e jurisprudência. 4. ed. São Paulo: Saraiva Educação, 2018.

OLIVEIRA, José Sebastião de; CARAPUNARLA, Humberto Luiz. Vencendo a paixão e a emoção nos conflitos familiares: a conciliação e a mediação como solução para os litígios na área de família. Revista de Formas Consensuais de Solução de Conflitos, v. 2, n. 1, p. 100-118, jan./jun. 2016. Disponível em: https://www.indexlaw.org/index.php/revistasolucoesconflitos/article/ view/1130/1123. Acesso em: 19 dez. 2019.

PEREIRA, Rodrigo da Cunha. Princípios fundamentais norteadores para o direito de família. Belo Horizonte: Del Rey, 2005.

PINTO, Carlos Alberto da Mota. Teoria geral do direito civil. Coimbra: Coimbra, 2005.

POPPER, Karl R. A lógica da pesquisa científica. Tradução Leonidas Hegenberg e Octanny Silveira de Mota. 2. ed. São Paulo: Cultrix, 2013.

QUIROSA, María Celia de La Cruz. Manual teórico práctico de mediación y conciliación. Buenos Aires: Ediciones Juridicas, 1999. RAMOS, Patrícia Pimentel de Oliveira Chambers. Poder familiar e guarda compartilhada: novos paradigmas do direito de família. 2. ed. São Paulo: Saraiva, 2016.

RODRIGUES, Horácio Wanderlei; GONÇALVES, Jéssica; LAHOZ, Maria Alice Trentini. Mediação na Resolução CNJ no 125/2010 e na Lei no 13.105/2015 (NCPC): uma análise crítica. Revista Direitos Sociais e Políticas Públicas (Unifafibe), v. 6, n. 1, p. 88-114, 2018. Disponível em: http://www.unifafibe.com.br/revista/index.php/direitos-sociais-politicas-pub/article/view/329. Acesso em: 14 dez. 2019.

RUIZ, Ivan Aparecido. Breves observações sobre a mediação no âmbito do direito de família. Revista Jurídica Cesumar-Mestrado, v. 3, n. 1, p. 7-38, 2003. Disponível em: https://periodicos.unicesumar.edu.br/index.php/revjuridica/article/view/386/391. Acesso em: 19 dez. 2019. 
RUIZ, Ivan Aparecido; NUNES, Taís Zanini de Sá Duarte. Breves reflexões acerca da mediação segundo a regulamentação do Conselho Nacional de Justiça (CNJ). Revista Direitos Sociais e Políticas Públicas (Unifafibe), v. 2, n. 1, p. 64-92, 2014. Disponível em: http://www.unifafibe.com.br/revista/index.php/direitos-sociais-politicas-pub/article/view/22. Acesso em: 8 dez. 2019.

SAMPAIO, Lia Regina Castaldi; BRAGA NETO, Adolfo. O que é mediação de conflitos. São Paulo: Brasiliense, 2007.

SAMPAIO JÚNIOR, José Herval. O papel do juiz na tentativa de pacificação social: a importância das técnicas de conciliação e mediação. Revista Opinião Jurídica, Fortaleza, v. 9, n. 13, p. 153-181, 2011. Disponível em: https://periodicos.unichristus.edu. br/opiniaojuridica/article/view/787. Acesso em: 28 set. 2019.

SCHREIBER, Anderson. Novos paradigmas da responsabilidade civil: da erosão dos filtros da reparação à diluição dos danos. 4. ed. São Paulo: Atlas, 2012.

SIQUEIRA, Dirceu Pereira; PAIVA, Caroline Zanetti. A utilização da mediação como forma de efetivação ao acesso à justiça e o princípio da dignidade da pessoa humana. Revista Eletrônica do Curso de Direito da UFSM, v. 11, n. 1, p. 180-197, 2016. Disponível em: https://periodicos.ufsm.br/revistadireito/article/view/20505/pdf. Acesso em: 19 dez. 2019.

SOUZA, Patrícia Verônica Nunes Carvalho Sobral de; FACHIN, Zulmar. O princípio da dignidade da pessoa humana como fundamento para o Estado contemporâneo: um olhar sob o viés dos direitos da personalidade. Revista Direitos Sociais e Políticas Públicas (Unifafibe), v. 7, n. 3, p. 311-340, 2019. Disponível em: http://www.unifafibe.com.br/revista/index.php/direitos-sociais-politicas-pub/article/view/610. Acesso em: 20 dez. 2019.

SZANIAWSKI, Elimar. Os direitos de personalidade e sua tutela. 2. ed. São Paulo: Revista dos Tribunais, 2005.

TARTUCE, Fernanda. Mediação nos conflitos civis. 5. ed. São Paulo: Método, 2019a.

TARTUCE, Fernanda. Mediação, autonomia e audiência inicial nas ações de família regidas pelo Novo Código de Processo Civil. 2017. Disponível em: http://www.fernandatartuce.com.br/wp-content/uploads/2017/05/Media\%C3\%A7\%C3\%A3o-autonomia-e-vontade-a\%C3\%A7oes-familiares-no-NCPC.pdf. Acesso em: 6 set. 2019.

TARTUCE, Fernanda. Processo civil no Direito de Família: teoria e prática. 4. ed. São Paulo: Método, $2019 \mathrm{~b}$.

VASCONCELOS, Carlos Eduardo. Mediação de conflitos e práticas restaurativas. 5. ed. Rio de Janeiro: Forense, 2017.

WARAT, Luis Alberto. Mediación, el derecho fuera de las normas: para una teoría no normativa del conflicto. Scientia luris, Londrina, v. 4, p. 3-18, 2000. Disponível em: http://www.uel.br/revistas/uel/index.php/iuris/article/view/11202/9966. Acesso em: 19 dez. 2019.

ZAPPAROLLI, Celia Regina. A experiência pacificadora da mediação: uma alternativa contemporânea para a implementação da cidadania e da justiça. In: MUZSKAT, Malvina Ester (org.). Mediação de conflitos: pacificando e prevenindo a violência. São Paulo: Summus, 2003. p. 49-76.

ZEHR, Howard. Trocando as lentes: um novo foco sobre o crime e a justiça. São Paulo: Palas Athena, 2008. 